\title{
The Relationship between frailty and
} depression among hospitalized older adults Mona Mohammed Ali Elkady ${ }^{1}$, Tomader Taha Abd ELRahman ${ }^{1}$, Mohamad Ahmad Alsadany ${ }^{1}$

1-Geriatrics and Gerontology Department, Faculty of Medicine, Ain Shams University

\begin{abstract}
Background: Frailty is a common geriatric syndrome with multiple negative health outcomes such as falls, reduced mobility, and loss of independence, hospitalization, disability and death. Depression is a common health problem among elderly that affects quality of life significantly. Both syndromes partially overlap, so comes the importance of studying the relationship between depression and frailty among hospitalized older adults.
\end{abstract}

Object: to assess the relationship between depression and frailty among hospitalized older adults admitted to the Geriatrics hospital at Ain Shams University in Cairo, Egypt.

Methods: A cross sectional study, included 100 hospitalized elderly patients, who were admitted to the Geriatrics hospital at Ain Shams University Hospitals. Participants were divided into two groups regarding presence of depression or not. Diagnosis of frailty was done by the Edmonton Frailty Scale. Diagnosis of depression was done according to DSM-IV criteria.

Results: A significant association between frailty and depression was found/, Major depression was found in $60 \%$ of frail elderly participants, Compared to only $20 \%$ among those non-frail participants.

Conclusion: Depression is highly prevalent among hospitalized frail older adults.

Keywords: Frailty, Depression, hospitalized, older adults.

\section{Background}

Frailty is one of the most serious global public health challenges. With population aging, a concomitant rise in the number of older adults with frailty is expected [1], which in turn places an increased pressure on health-care systems worldwide [2].

Frailty is a clinically recognizable state of older adults with increased vulnerability, resulting from ageassociated declines in physiologic reserve and function across multiple organ systems, such that the ability to cope with every day or acute stressors is compromised [3].

The frailty syndrome is mostly associated with advanced age. However, frailty syndrome is not a variant of normal aging, and it is considered a separate category. Parallel to functional, psychological, and musculoskeletal changes, there are also change in the organ systems and homeostatic responses in frailty [4]. Late-life depression is an important public health problem due to its devastating consequences [5]. It is associated with an increased risk of morbidity; decreased physical, cognitive, and social functioning [6]. Despite its high prevalence, healthcare systems in low- and middle-income countries are not resilient enough to deal with mental health problems including depressive disorders [7].

An overlap between frailty and depression was demonstrated, and a positive association between the two syndromes has been indicated, they are distinct constructs that share moderate overlap [8] [9].

Similar biological mechanisms have been hypothesized to account for both syndromes (frailty and depression) as cardiovascular risk factors [10] [11], and inflammation [12] [13].

The aim from this study was to assess the relationship between depression and frailty among hospitalized older adults admitted to the Geriatrics hospital at Ain Shams University in Cairo, Egypt.

\section{Materials and Methods}

A cross-sectional study was conducted in the Geriatric hospital, Ain Shams University Hospitals, Cairo, Egypt. 
A total 100 older adults participants, 60 years and older, men and women, were recruited, during the time from December 2019 and June 2020, from the inpatient unit, Geriatric hospital, at Ain Shams University Hospitals. The participants then were divided, according to due presence or absence of frailty, into two groups: (a) case group that included 50 frail participants and (b) control group that included 50 nonfrail participants.

Inclusion criteria: All older adults patients who were admitted to the inpatient unit in Geriatric hospital, Ain Shams University Hospitals, from December 2019 and June 2020, were consider eligible for inclusion.

Exclusion criteria: we excluded those who did not give a consent to participate in this study, patients who had delirium at the time of assessment, patients with terminally ill medical condition, patients with any Psychiatric disorder or substance abuse, and patients who were taking antidepressants.

Methods: All participants were subjected to Comprehensive geriatric assessment, including complete medical history and physical examination, cognitive assessment function by the Arabic version [14] of MMSE (mini-mental status examination) [15], functional assessment by ADL (activities of daily living) [16] and IADL (Instrumental activities of daily living) [17].

Assessment of depression was done according to DSMIV criteria [18].

For diagnosis of depression at least 5 of these symptoms should be present during the same 2-week period (including at least one of the symptoms diminished interest/pleasure or depressed mood) (1) depressed mood, (2) diminished interest or loss of pleasure in almost all activities (anhedonia), (3) significant weight change or appetite disturbance, (4) sleep disturbance either insomnia or hypersomnia, (5) psychomotor agitation or retardation, (6) fatigue or loss of energy, (7) feelings of worthlessness, (8) diminished ability to think or concentrate indecisiveness, and (9) recurrent thoughts of death, recurrent suicidal ideation, or a suicide attempt.

Diagnosis of Assessment of frailty was done according to the Edmonton Frail Scale (EFS) [19].

The EFS assesses nine domains of frailty (cognition, general health status, functional independence, social support, medication usage, nutrition, mood, continence, functional performance) [20].

\section{Statistical analysis}

The statistical analysis was performed with the SPSS 22.0 package program. Descriptive statistics were carried out for all variables and expressed as mean and \pm SD for quantitative data, whereas qualitative data were expressed as numbers and percentages.

Chi-Square test was used to examine the relationship between two qualitative variables Fisher's exact test was used to examine the relationship between two qualitative variables when the expected count is less than 5 in more than $20 \%$ of cells. P. value $\leq 0.05$ was considered significant. $\mathrm{P}>0.05$ was considered Nonsignificant.

\section{Results:}

Table (1) shows that half of the total study participants $(50 \%)$ were frail. Among the frail participants, $17 \%$ had severe frailty, $21 \%$ had moderate frailty, $12 \%$ had mild frailty. Prefrailty status was found in $13 \%$ were prefrail. Aassessment of depression among all study participants showed that $61 \%$ of the study participants were depressed. Major depression was found higher than minor depression (40\% vs $2 \%$ respectively).

Table (2) showed a significant association between frailty status with each of increasing age, lower educational level, and living alone either being divorced or widow.

Regarding comorbidities, a significant association was found between frailty and each of presence of hypertension and history of cerebrovascular stroke, and poor nutritional status either malnourished or being at risk for malnutrition.

Also, there was a highly significant association between frailty status and both risk of fall and poor functional status assessed by ADL and IADL.

Table (3) showed that depression was significantly associated with increasing age, female gender, and obesity. Regarding co-morbidities, presence of COPD/asthma and poor nutritional status was significantly associated with depression.

Also, depression was found to be associated with increasing risk of fall and with poor functional level as assessed by ADL and IADL.

Table (4) showed a significant positive association between major depression and frailty ( $p$ value $<0.001$ ). 
Table 1. Frailty and depression status for whole study participants.

\begin{tabular}{|c|c|c|c|}
\hline & & & Number (\%) \\
\hline \multirow[t]{5}{*}{$\begin{array}{l}\text { Assessment for frailty status (EFS } \\
\text { score) }\end{array}$} & \multirow[t]{2}{*}{$\begin{array}{l}\text { Not frail } \\
(\mathbf{n}=\mathbf{5 0})\end{array}$} & Normal & $37(37 \%)$ \\
\hline & & Pre-frail & $13(13 \%)$ \\
\hline & \multirow{3}{*}{$\begin{array}{l}\text { Frail } \\
(n=50)\end{array}$} & mild frailty & $12(17 \%)$ \\
\hline & & moderate frailty & $21(21 \%)$ \\
\hline & & severe frailty & $17(12 \%)$ \\
\hline \multirow[t]{3}{*}{ Assessment for depression } & Not depressed & & $39(39 \%)$ \\
\hline & \multirow[t]{2}{*}{ Depressed $(n=61)$} & Major depression & $40(40 \%)$ \\
\hline & & Minor depression & $21(21 \%)$ \\
\hline
\end{tabular}

Table 2. Comparison between frail and non-frail participants regarding Socio-demographic data \& clinical characteristics.

\begin{tabular}{|c|c|c|c|c|}
\hline & & $\begin{array}{l}\text { Non -Frail } \\
\text { Mean } \pm \text { SD } \\
\text { N }(\%)\end{array}$ & $\begin{array}{l}\text { Frail } \\
\text { Mean } \pm \text { SD } \\
\text { N }(\%)\end{array}$ & $\begin{array}{l}\text { Significance: } \\
\text { p-Value }\end{array}$ \\
\hline \multicolumn{2}{|l|}{ Age } & $68.88 \pm 5.97$ & $74.04 \pm 7.32$ & $<0.001(\mathrm{~T})$ \\
\hline \multirow[t]{2}{*}{ Sex } & Male & $25(50 \%)$ & $23(46 \%)$ & \multirow[t]{2}{*}{$0.689(C)$} \\
\hline & Female & $25(50 \%)$ & $27(54 \%)$ & \\
\hline \multirow[t]{3}{*}{ Education } & Illiterate & $19(38 \%)$ & $33(66 \%)$ & \multirow[t]{3}{*}{$0.013(\mathrm{C})$} \\
\hline & educated $<6$ & $7(14 \%)$ & $6(12 \%)$ & \\
\hline & educated $\geq 6$ & $24(48 \%)$ & $11(22 \%)$ & \\
\hline \multirow{3}{*}{$\begin{array}{l}\text { Marital } \\
\text { status }\end{array}$} & Married & $36(72 \%)$ & $24(48 \%)$ & \multirow[t]{3}{*}{$0.029(F)$} \\
\hline & Divorced & $1(2 \%)$ & $1(2 \%)$ & \\
\hline & Widow & $13(26 \%)$ & $25(50 \%)$ & \\
\hline \multirow[t]{3}{*}{ Smoking } & Nonsmoker & $22(44 \%)$ & $23(46 \%)$ & \multirow[t]{3}{*}{$0.615(C)$} \\
\hline & Smoker & $21(42 \%)$ & $17(34 \%)$ & \\
\hline & Ex-smoker & $7(14 \%)$ & $10(20 \%)$ & \\
\hline \multirow[t]{4}{*}{ BMI } & Obese & $16(32 \%)$ & $19(38 \%)$ & \multirow[t]{4}{*}{$0.399(F)$} \\
\hline & Overweight & $14(28 \%)$ & $17(34 \%)$ & \\
\hline & Normal & $20(40 \%)$ & $13(26 \%)$ & \\
\hline & Under-weight & $0(0 \%)$ & $1(2 \%)$ & \\
\hline \multirow{9}{*}{ 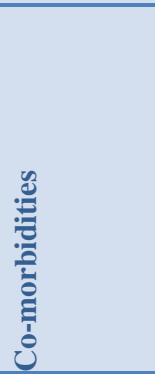 } & DM & $19(38 \%)$ & $27(54 \%)$ & $0.108(C)$ \\
\hline & HTN & $23(46 \%)$ & $33(66 \%)$ & $0.044(C)$ \\
\hline & Liver disease & $15(30 \%)$ & $12(24 \%)$ & $0.499(\mathrm{C})$ \\
\hline & Heart failure / IHD / Arrhythmia & $13(26 \%)$ & $21(42 \%)$ & $0.091(\mathrm{C})$ \\
\hline & COPD/Asthma & $9(18 \%)$ & $13(26 \%)$ & $0.334(\mathrm{C})$ \\
\hline & Stroke & $3(6 \%)$ & $13(26 \%)$ & $0.006(\mathrm{C})$ \\
\hline & Malignancy & $1(2 \%)$ & $4(8 \%)$ & $0.362(\mathrm{~F})$ \\
\hline & UI & $6(12 \%)$ & $10(20 \%)$ & $0.275(\mathrm{C})$ \\
\hline & Malnutrition/at risk(by MNA) & $21(42 \%)$ & $42(84 \%)$ & $<0.001(\mathrm{C})$ \\
\hline \multicolumn{2}{|c|}{ RISK Of fall (by TUGT) } & $35(70 \%)$ & $1(2 \%)$ & $<0.001(C)$ \\
\hline \multirow[t]{3}{*}{ ADL } & Independent & $45(90 \%)$ & $14(28 \%)$ & \multirow[t]{3}{*}{$<0.001(\mathrm{C})$} \\
\hline & Assisted & $4(8 \%)$ & $23(46 \%)$ & \\
\hline & Dependent & $1(2 \%)$ & $13(26 \%)$ & \\
\hline \multirow[t]{3}{*}{ IADL } & Assisted & $41(82 \%)$ & $3(6 \%)$ & \multirow[t]{3}{*}{$<0.001(C)$} \\
\hline & Dependent & $8(16 \%)$ & $26(52 \%)$ & \\
\hline & Independent & $1(2 \%)$ & $21(42 \%)$ & \\
\hline
\end{tabular}

${ }^{(T)}$ Student t-test. ${ }^{(C)}$ Chi-Square test. ${ }^{(F)}$ Monte Carlo Fisher's Exact test.BMI= body mass index. DM= Diabetes mellitus, HTN= Hypertension, IHD= ischemic heart disease, MNA= Mini-nutritional assessment. TUGT = timed up and go test; $A D L=$ Activities of daily living; $I A D L=$ instrumental activities of daily living. 
Table 3. Comparison between depressed and non-depressed participants regarding Socio-demographic data \& clinical characteristics.

\begin{tabular}{|c|c|c|c|c|}
\hline & & $\begin{array}{l}\text { Non Depressed }(n=39) \\
\text { Mean } \pm \text { SD } \\
\text { N }(\%)\end{array}$ & $\begin{array}{l}\text { Depressed }(n=61) \\
\text { Mean } \pm \text { SD } \\
\text { N }(\%)\end{array}$ & $\begin{array}{l}\text { Significance: } \\
\text { p-Value }\end{array}$ \\
\hline \multicolumn{2}{|l|}{ Age } & $68.69 \pm 5.69$ & $73.23 \pm 7.44$ & $0.001(\mathrm{~T})$ \\
\hline \multirow[t]{2}{*}{ Sex } & male & $25(52.08 \%)$ & $23(47.92 \%)$ & \multirow[t]{2}{*}{$0.01(C)$} \\
\hline & female & $14(26.92 \%)$ & $38(73.08 \%)$ & \\
\hline \multirow[t]{3}{*}{ Education } & illiterate & $15(28.85 \%)$ & $37(71.15 \%)$ & \multirow[t]{3}{*}{$0.09(\mathrm{C})$} \\
\hline & educated <6 & $7(53.85 \%)$ & $6(46.15 \%)$ & \\
\hline & educated $\geq 6$ & $17(48.57 \%)$ & $18(51.43 \%)$ & \\
\hline \multirow{3}{*}{$\begin{array}{l}\text { Marital } \\
\text { status }\end{array}$} & married & $27(45 \%)$ & $33(55 \%)$ & \multirow[t]{3}{*}{$0.29(F)$} \\
\hline & divorced & $\mathbf{0}(\mathbf{0} \%)$ & $2(100 \%)$ & \\
\hline & widow & $12(31.58 \%)$ & $26(68.42 \%)$ & \\
\hline \multirow[t]{3}{*}{ Smoking } & nonsmoker & $14(31.11 \%)$ & $31(68.89 \%)$ & \multirow[t]{3}{*}{$0.201(C)$} \\
\hline & smoker & $19(50 \%)$ & $19(50 \%)$ & \\
\hline & Ex-smoker & $6(35.29 \%)$ & $11(64.71 \%)$ & \\
\hline \multirow[t]{4}{*}{ BMI } & Obese & $8(22.86 \%)$ & $27(77.14 \%)$ & \multirow[t]{4}{*}{$0.045(F)$} \\
\hline & Overweight & $14(45.16 \%)$ & $17(54.84 \%)$ & \\
\hline & Normal & $16(48.48 \%)$ & $17(51.52 \%)$ & \\
\hline & Under-weight & $1(100 \%)$ & $0(\mathbf{0 \%})$ & \\
\hline \multirow{9}{*}{ 递 } & DM & $16(34.78 \%)$ & $30(65.22 \%)$ & $0.425(\mathrm{C})$ \\
\hline & HTN & $18(32.14 \%)$ & $38(67.86 \%)$ & $0.113(\mathrm{C})$ \\
\hline & Liver disease & $13(48.15 \%)$ & $14(51.85 \%)$ & $0.254(\mathrm{C}))$ \\
\hline & $\begin{array}{l}\text { Heart failure / IHD } \\
\text { /Arrhythmia }\end{array}$ & $11(32.35 \%)$ & $23(67.65 \%)$ & $0.328(C)$ \\
\hline & COPD/Asthma & $4(18.18 \%)$ & $18(81.82 \%)$ & $0.023(\mathrm{C})$ \\
\hline & Stroke & $4(25 \%)$ & $12(75 \%)$ & $0.21(\mathrm{C})$ \\
\hline & Malignancy & $2(40 \%)$ & $3(60 \%)$ & $1.00(\mathbf{F})$ \\
\hline & UI & $4(25 \%)$ & $12(75 \%)$ & $0.21(\mathrm{C})$ \\
\hline & $\begin{array}{l}\text { Malnutrition/at risk } \\
\text { (by MNA) }\end{array}$ & $17(27 \%)$ & $46(73 \%)$ & $0.001(\mathrm{C})$ \\
\hline \multicolumn{2}{|c|}{ RISK Of fall (by TUGT) } & $16(25 \%)$ & $48(75 \%)$ & $<0.001(\mathrm{C}))$ \\
\hline \multirow[t]{3}{*}{ ADL } & Independent & $29(49.15 \%)$ & $30(50.85 \%)$ & \multirow[t]{3}{*}{$0.025(\mathrm{C})$} \\
\hline & Assisted & $5(18.52 \%)$ & $22(81.48 \%)$ & \\
\hline & Dependent & $5(35.71 \%)$ & $9(64.29 \%)$ & \\
\hline \multirow[t]{3}{*}{ IADL } & Assisted & $26(59.09 \%)$ & $18(40.91 \%)$ & \multirow[t]{3}{*}{$<0.001(\mathrm{C})$} \\
\hline & Dependent & $6(17.65 \%)$ & $28(82.35 \%)$ & \\
\hline & Independent & $7(31.82 \%)$ & $15(68.18 \%)$ & \\
\hline
\end{tabular}

Table (4): Comparison between frail and non-frail participants regarding depression and depressive symptoms

\begin{tabular}{|c|c|c|c|c|}
\hline & & \multicolumn{2}{|c|}{ Frailty status } & \multirow{2}{*}{$\begin{array}{l}\text { Significance: } \\
\text { p. .value }\end{array}$} \\
\hline & & Non Frail & Frail & \\
\hline \multirow{3}{*}{$\begin{array}{l}\text { Assessment by } \\
\text { DSM-IV }\end{array}$} & Major depression & $10(20 \%)$ & $30(60 \%)$ & \multirow[t]{3}{*}{$<0.001(\mathrm{C})$} \\
\hline & Minor depression & $12(24 \%)$ & $9(18 \%)$ & \\
\hline & No depression & $28(56 \%)$ & $11(22 \%)$ & \\
\hline
\end{tabular}




\section{DISCUSSION}

Frailty is a common, multi-factorial, geriatric syndrome that could lead to disability, functional dependence, and depression [21]. Depression may predict indicators of frailty due to the decrease in social ties, less physical activities, increase in fall risk, weight loss, and malnutrition. All these factors may increase the perpetuation of affective symptoms typical of depression including sadness, anhedonia, and helplessness [22] [23].

It is unclear whether depression contributes to frailty or vice versa, or if both disorders co-occur in the same patients independently of one another, but research confirms the pathophysiological processes and biomarkers present in both. The current study was conducted to investigate the relationship between frailty and depression in hospitalized older adults admitted to the Geriatric unit in Ain Shams University Hospitals, Cairo, Egypt .The study included 100 elderly participants who were sex- matched.

The association between depression and frailty which was the main concern in our work,. We found that depression was statistically significantly higher among frail elderly participants, as $78 \%$ of the frail participants had depression in general, either major depression $(60 \%)$ or minor (subsyndromal) depression $(18 \%)$ (p. value $<0.001)$. This was consistent with other previous studies, such as data from the FIBRA (Fragility in Elderly Brazilians) revealed that $31.8 \%$ of frail elderly had depressive symptoms, as assessed by the GDS-15 [24].

Comparing socio-demographic characteristics of the study participants in relation to their frailty status revealed a significant association with increasing age and frailty as mean age of frail participants was (74.04 \pm 7.32$)$ compared to $(68.88 \pm 5.97)$ in non-frail ( $p$ value $<0.001)$. This comes in agreement of the literature that the known fact that age is an important risk factor to frailty, and with many other studies that showed the influence of the aging process on the emergence of frailty [25] [26] [27] [28].

We did not find any significant gender difference in relation to frailty status. In line with our result, other studies also did not find an association between gender and frailty, and they did not consider gender a risk factor for adverse outcomes in old age [28] [29].

Frail participants had a significantly higher percentage of illiteracy as compared to non-frail participants $(66 \%$ versus $38 \%$. p. value 0.013 ). Studies suggested that low health literacy levels are predictors of disparaging health outcomes [30], and are associated with higher mortality rates [31]. Also, we found a significant association between unstable marital status and frailty as $50 \%$ of frail participants were widow/erin comparison to $36 \%$ of the non-frail (p. value 0.02 ).

We did not find any significant association between BMI and frailty, in contrary to the results of Hubbard et al, [32] who found an association between BMI and frailty showed a U-shaped curve.Also, we did not an association between frailty and smoking status in contrast to findings shown by other studies as Kojima et al, [33]. This could be due our smaller sample size.

Regarding co-morbidities among our study participants, we found a significant association between hypertension and frailty as $66 \%$ of frail participants were hypertensive compared to $46 \%$ in the non-frail (p. value 0.044). Stroke also was found associated with frailty as $26 \%$ of frail participants had a history of stroke compared to only $6 \%$ of non-frail(p. value 0.006). Frailty is known to be associated with comorbidities, even though the frailty syndrome may exist without the presence of co morbidity [34]. Studies have shown that elderly individuals who experience associated co-morbidities seem to be more predisposed to frailty and that the prognosis for such a condition depends on the clinical manifestations exhibited [29] [35], but our study showed no association with other co morbidities such as, diabetes mellitus, heart failure, COPD, liver diseases and cancer.

Also, we found a significant association between frailty and poor nutritional status, as $84 \%$ of frail participants had poor nutritional status (malnourished or at risk of malnutrition) compared to $42 \%$ of non-frail participants (p. value 0.001)]. This came in agreement with other studies that revealed an association between frailty and nutritional deficiencies [36] [37].

Regarding the functional status and the presence of disability as expected risk factor and part of the pathogenesis of the frailty syndrome,we assessed the functional status and found that $98 \%$ of frail participants had risk of fall, compared to only $30 \%$ of non-frail participants (p. value <0.001). Also, a significant lower functional status indicated by ADL and IADL was noted among frail participants compared to non-frail ( $\mathrm{p}$. value>0.001). These findings were like the results found in other previous studies [38] [39] [40].

Comparison of socio-demographic characteristics of the study participants in relation to presence or absence of depression showed that depression was significantly associated with increasing age (p. value 0.001). This could be explained by the increase in chronic diseases, stressful life events, and polypharmacy that increase with aging and contribute to occurrence of depression. This finding comes in agreement with one studies [41] that found the same association, but comes in contrary to another one [42] which found no significant association between depression and increasing age 
among Chinese older adults, and this could be due to their larger sample size (4945 older adults) and their sampling method.

Also, a significant association between depression and female gender was found (p. value 0.01), and this may be due to their longer life expectancy, poor social support, or exposure to psychosocial stressor. This finding comes in agreement with other studies [43] [44] but did not agree with others who did find such association [45].

Regarding BMI in relation to depression, we found a significant association between higher BMI (or obesity) and depression, as $77 \%$ of the depressed patients were obese compared to $22.86 \%$ in non-depressed (p. value 0.045). Previous studies have supported such association [46] [47] [48] However we have not ruled a possible bidirectional causal relationship between higher BMI and depression, as suggested by earlier systematic reviews of longitudinal studies [49]. Further research is required to explore the causal role of depression on body mass index and obesity. The power for testing the relationship from depression to BMI is currently limited, but as more genetic variants are identified for depression this relationship can be more comprehensively explored [46].

We did not find any association between depression and certain demographic variables as marital status and educational level. This agrees with some previous studies that found lower education level and being unmarried did not increase the risk of depression [45] [50], but this is not the same in other studies [42] [51] that showed significant association between both unstable marital state and low education with depression.

Regarding co-morbidities and its relation to depression in our study, we did not find any significant association except with chronic chest problems and poor nutritional status, as $81 \%$ of depressed participants had chronic chest problem, and $73 \%$ of them had poor nutritional status either malnourished or at risk for malnutrition ( $\mathrm{p}$. value $0.23 ; 0.001$ respectively). But this was contradictory to others [45] [52] who found associations between depression and other co morbidities such as (diabetes, arthritis, cardiac diseases, and cancer).

The association between poor nutrition and depression among older adults, either community-dwelling or hospitalized, was supported by other previous studies [53] who found that risk of developing depression was four times as high in elderly with nutritional deficits as in those without.

We found a significant association between functional disability and depression. $75 \%$ of the depressed participants had risk of fall compared to only $25 \%$ in the non-depressed participants (p. value <0.001). Also, lower functional levels were found in depressed participants compared to those non-depressed as indicated with lower ADL and IADL (p. value 0.025; $<0.001$ respectively), and this comes in agreement with other studies [45, 52], but this was in contrast to another one [54] who showed that functional status was not affected in subjects with minor or severe depressive symptoms.

\section{Conclusion}

Depression is highly prevalent among hospitalized frail older adults.

\section{Ethical considerations}

An approval for the study was granted before starting the subject's recruitment process. Informed verbal consent was taken from all participants recruited in this study. The study methodology was reviewed and approved by the Research Review Board of the Geriatrics and Gerontology Department, Faculty of Medicine, Ain Shams University assuring the confidentiality of all participants .support for this work that could have influenced its outcome.

\section{References}

1. Mousa A, Savva GM, Mitnitski A, et al (2018): Is frailty a stable predictor of mortality across time? Evidence from the Cognitive Function and Ageing Studies. Age Ageing; 47(5): 721-27.

2. Ilinca S and Calciolari S (2015): The patterns of health care utilization by elderly Europeans: frailty and its implications for health systems. Health Serv Res; 50(1): 305-20.

3. Fried LP, Hadley EC, Walston JD, et al (2005): From bedside to bench: research agenda for frailty. Sci Aging Knowledge Environ; (31):24.

4. Morley JE, Vellas BG, Abellan van Kan, et al (2013): Frailty consensus: a call to action. Journal of the American Medical Directors Association, 14(6): 392-97.

5. Fiske A, Wetherell JL, GatzM (2009): Depression in older adults. Annu Rev ClinPsychol; 5:363-89.

6. Blazer DG (2003): Depression in late life: review and commentary. J GerontolABiolSci Med Sci; 58(3): 249-65.

7. World Health Organization (2014): Social determinants of mental health. Vol; 978. World Health Organization Geneva.

8. Mezuk B, Edwards L, Lohman M, et al (2012): Depression and frailty in later life: a synthetic review. Int J Geriatr Psychiatry; 27(9):879-92.

9. Buigues C, Padilla-Sánchez C, Garrido JF, et al (2015): The relationship between depression and frailty syndrome: a systematic review. Aging Ment Health;19(9):762-72.

10. Newman AB, Gottdiener JS, McBurnie MA, et al (2001): Associations of subclinical cardiovascular disease with frailty. J Gerontol A Biol Sci Med Sci; 56(3):158-66.

11. Paulson D, Lichtenberg PA (2012): Vascular depression: an early warning sign of frailty. Aging Ment Health; 17(1):8593.

12. Walston J, McBurnie M, Newman A, et al (2002): Frailty and activation of the inflammation and coagulation systems with and without clinical comorbidities: results from the cardiovascular health study. Arch Intern Med; 162(20):2333-41.

13. Leng SX, Xue Q-L, Tian J, et al (2007): Inflammation and frailty in older women. J Am Geriatr Soc; 55(6):864-71.

14. El-OkI MA, EI Banouby MH, and EI Etrebi A (2002): Prevalence of Alzheimer dementia and other causes of dementia in Egyptian elderly. MD Thesis, Faculty of Medicine, Ain Shams University.

15. Folstein MF, Folstein SE, and McHugh PR (1975): Mini Mental State: a practical method for grading the cognitive state of 
patients for the clinician. J Psychiatr Res; 12:189-98.

16. Katz S, Ford AB, Moskowitz RW, et al (1963): Studies of illness in the aged: The index of ADL: A standardized measure of biological and psychosocial function. JAMA;185(12): 914-919.

17. Lawton MP and Brody EM (1969): Assessment of older people: self-maintaining and instrumental activities of daily living. Gerontologist; 9 (3):179-186.

18. American Psychiatric Association (2013): American Psychiatric Association. Diagnostic and Statistical Manual of Mental Disorders. Fifth edition. Washington, DC

19. Rolfson DB, Majumda SR, Tsuyuki RT, et al (2006): Validity and reliability of the Edmonton Frail Scale. Age Ageing;35(5):526-9.

20. Perna S, Francis MDA, Bologna C,et al (2017): Performance of Edmonton Frail Scale on frailty assessment: its association with multi-dimensional geriatric conditions assessed with specific screening tools. BMC geriatrics; 17(1): 1-8.

21. Fugate Woods N, LaCroix A Z, Gray S L, et al (2005): Frailty: emergence and consequences in women aged 65 and older in the Women's Health Initiative Observational Study. Journal of the American Geriatrics Society; 53(8):1321-30.

22. Hajek A, Brettschneider C, Posselt T, et al (2016): Predictors of Frailty in Old Age - Results of a Longitudinal Study. J. Nutr. Health Aging;20(9): 952-57.

23. Paulson D, Lichtenberg PA (2013): Vascular depression: an early warning sign of frailty. Aging Ment Health;17(1): 85-93.

24. Nascimento PP, Batistoni S S, Neri AL (2016): Frailty and depressive symptoms in older adults: data from the FIBRA study-UNICAMP. Psico Reflex Crit; 29:16.

25. Ahmed N, Mandel R, Fain MJ (2007): Frailty: an emerging geriatric syndrome. The American journal of medicine; 120(9):748-53.

26. Carey EC, Covinsky KE, Lui LY, et al (2008): Prediction of mortality in community-living frail elderly people with long-term care needs. Journal of the American Geriatrics Society; 56(1): 68-75.

27. Ensrud KE, Ewing SK, Cawthon PM, et al (2009): A comparison of frailty indexes for the prediction of falls, disability, fractures, and mortality in older men. Journal of the American Geriatrics Society;57(3): 492-98.

28. Ávila-Funes JA, Amieva H, Barberger-Gateau P, et al (2009): Cognitive impairment improves the predictive validity of the phenotype of frailty for adverse health outcomes: the three-city study. Journal of the American Geriatrics Society;57(3): 453-61.

29. Sarkisian CA, Gruenewald T L, John Boscardin W, et al (2008): Preliminary evidence for subdimensions of geriatric frailty: the MacArthur study of successful aging. Journal of the American Geriatrics Society; 56(12): 2292-97.

30. Baker DW, Gazmararian JA, Williams MV, et al (2002): Functional health literacy and the risk of hospital admission among Medicare managed care enrollees. American Journal of Public Health; 92(8):1278-83.

31. Baker DW, Wolf MS, Feinglass J, et al (2007): Health literacy and mortality among elderly persons. Archives of Internal Medicine; 167(14): 1503-9.

32. Hubbard RE, Lang IA, Llewellyn DJ, et al (2010): Frailty, body mass index, and abdominal obesity in older people. Journals of Gerontology Series A: Biomedical Sciences and Medical Sciences; 65(4):377-81.

33. Kojima G, Iliffe S, J Stephen, et al (2018): Does current smoking predict future frailty? The English longitudinal study of ageing. Age Ageing; 47(1):126-31.

34. Fried LP, Ferrucci L, DarerJ, et al (2004): Untangling the concepts of disability, frailty, and comorbidity: implications for improved targeting and care. The Journals of Gerontology Series A: Biological Sciences and Medical Sciences; 59(3):25563.

35. Hackstaff L (2009): Factors associated with frailty in chronically ill older adults. Social work in health care; 48(8):798-11.

36. Bollwein J, Volkert D, Diekmann R, et al (2013): Nutritional status according to the mini nutritional assessment (MNA $\left.{ }^{\circledR}\right)$ and frailty in community dwelling older persons: a close relationship. The journal of nutrition, health \& aging; 17(4):351 56.

37. Dorner T E, Luger E, Tschinderle J,et al (2014): Association between nutritional status (MNA®-SF) and frailty (SHARE-FI) in acute hospitalised elderly patients. The journal of nutrition, health \& aging;18(3): 264-69.

38. Avlund K (2010): Fatigue in older adults: an early indicator of the aging process? Aging Clin Exp Res; 22(2): 100-15.

39. Simo es LA, Dias JM, Marinho KC, et al (2010): Relationship between functional capacity assessed by walking test and respiratory and lower limb muscle function in communitydwelling elders. Rev Bras Fisioter; 14(1):24-30.

40. Wennie Huang WN, Perera S, Vanswearingen J,et al (2010): Performance measures predict onset of activity of daily living difficulty in community dwelling older adults. J Am GeriatrSoc; 58(5): 844-52.

41. Yu J, Li J, Cuijpers P, et al (2012): Prevalence and correlates of depressive symptoms in Chinese older adults: A population-based study. International journal of geriatric psychiatry; 27(3): 305-12

42. Islam FMA (2019): Psychological distress and its association with socio-demographic factors in a rural district in Bangladesh: a cross-sectional study. PloS one;14(3):e0212765.

43. Nakulan A, Sumesh TP, Kumar S, et al (2015): Prevalence and risk factors for depression among community resident older people in Kerala. Indian J Psychiatry; 57(3): 262-66.

44. Lotfaliany M, Hoare E, Jacka FN, et al (2019): Variation in the prevalence of depression and patterns of association, sociodemographic and lifestyle factors in community-dwelling older adults in six low-and middle-income countries. J Affect Disord; 251:218-26.

45. Peltzer K,Phaswana-Mafuya N (2013): Depression and associated factors in older adults in South Africa. Global Health Action; 6:1-9.

46. Tyrrell J, Mulugeta A, Wood AR, et al (2019): Using genetics to understand the causal influence of higher BMI on depression. International journal of epidemiolog; 48(3): 834-48.

47. Onyike CU, Crum RM., Lee HB, et al(2003): Is obesity associated with major depression? Results from the Third National Health and Nutrition Examination Survey. American journal of epidemiology;158(12):1139-47.

48. Scott KM, McGee MA, Wells JE, et al (2008): Obesity and mental disorders in the adult general population. J Psychosom Res; 64(1): 97-105.

49. Luppino FS, de Wit LM, Bouvy P F, et al (2010): Overweight, obesity, and depression: a systematic review and meta-analysis of longitudinal studies. Archives of general psychiatry;67(3): 220-29.

50. Cole MG, Dendukuri N (2003): Risk factors for depression among elderly community subjects: a systematic review and meta-analysis. American journal of psychiatry;160(6):1147-56.

51. Aranda MP, Chae DH, Lincoln KD, et al (2012): Demographic correlates of DSM-IV major depressive disorder among older African Americans, Black Caribbeans, and non-Hispanic Whites: results from the National Survey of American Life. International journal of geriatric psychiatry; 27(9): 940-47.

52. Moussavi S, Chatterji S, Verdes E, etal (2007): Depression, chronicdiseases, and decrementsinhealth: resultsfrom the World Health Surveys. Lancet ; 370:851-58.

53. CabreraMAS, MesasAE, Garcia ARL, et al (2007): Malnutrition and depression among community-dwelling elderly people. J Am Med Dir Assoc; 8(9): 582-84.

54. German L, Feldblum I, Bilenko N, et al (2008): Depressive symptoms and risk for malnutrition among hospitalized elderly people. Nutr Health Aging ;12: 313-18.

55. Smoliner C, Norman K, Wagner KH, et al (2009): Malnutrition and depression in the institutionalised elderly. $\mathrm{Br} \mathrm{J}$ Nutr 102(11): 1663-67. 